\title{
Low-dose CT screening can reduce cancer mortality: A meta-analysis
}

\section{SUMMARY}

OBJECTIVE: Lung cancer is the leading cause of cancer-related death. To reduce lung cancer mortality and detect lung cancer in early stages, low dose CT screening is required. A meta-analysis was conducted to verify whether screening could reduce lung cancer mortality and to determine the optimal screening program.

METHODS: We searched PubMed, Web of Science, Cochrane library, ScienceDirect, and relevant Chinese databases. Randomized controlled trial studies with participants that were smokers older than 49 years (smoking >15 years or quit smoking 10 or 15 years ago) were included. RESULTS: Nine RCT studies met the criteria. LDCT screening could find more lung cancer cases $(R R=1.58,95 \% C l=1.25-1.99, P<0.001)$ and more stage I lung cancers $(R R=3.45,95 \% \mathrm{Cl}=2.08-5.72, P<0.001)$ compared to chest- $X$ ray or the no screening group. This indicated a statistically significant reduction in lung-cancer-specific mortality ( $R R=0.84,95 \% \mathrm{Cl}=0.75-0.95, P=0.004)$, but without a statistically reduction in mortality due to all causes $(R R=1.26,95 \% \mathrm{Cl}=0.89-1.78, P=0.193)$. Annually, $L D C T$ screening was sensitive in finding more lung cancers.

CONCLUSIONS: Low-dose CT screening is effective in finding more lung cancer cases and decreasing the deaths from lung cancer. Annual low-dose CT screening may be better than a biennial screening to detect more early-stage lung cancer cases.

KEYWORDS: Randomized controlled trial. Meta-analysis. Triage. Early Detection of Cancer. Tomography, X-Ray Computed.

\section{INTRODUCTION}

Lung cancer is among the most frequently diagnosed cancer types and is the leading cause of cancer deaths, with 1.82 million new cases and 1.6 million deaths in $2012^{1,2}$. Lung cancer has a poor prognosis and a relatively low five-year relative survival ratio in relation to all types of cancer; 5-year survival in Europe ranges from $9.6 \%$ in the UK to $17.9 \%$ in Austria. Lung cancer patients have poor outcomes of treatment, resulting from the fact that most cases are diagnosed in the advanced stage of the disease. Nowadays, some studies, like the NLST, advocate that screening for lung cancer in specific high-risk

DATE OF SUBMISSION: 27-Mar-2019

DATE OF ACCEPTANCE: 11-Jun-2019

CORRESPONDING AUTHOR: Yehuan SUn

Department of Epidemiology and Health Statistics, School of Public Health,

Anhui Medical University, No. 81 Meishan Road, Hefei, Anhui 230032, China

Email: yhsun_ahmu_edu@yeah.net 
groups of smokers could reduce mortality ${ }^{3}$. The EU Position Statement (EUPS) argues that lung cancer screening with LDCT could save lives, and planning for implementation throughout Europe has started ${ }^{4}$. A meta-analysis containing nine randomized controlled trials and review articles up to 2013 showed that LDCT screening for lung cancer resulted in the detection of a greater total of lung cancer cases, stage I lung cancers, and decreased lung cancer-specific mortality ${ }^{5}$.

Apart from verifying whether LDCT screening could reduce mortality due to lung cancer in high-risk smokers, we also explored whether a less frequent screening scenario, like biennial screening, could be equally effective as the annual screening? UPS also considered the biennial screening scenario before ${ }^{6}$.

\section{METHODS}

Data source and search strategy

Published studies were extensively searched through PubMed, Web of Science, Cochrane library, ScienceDirect (SD), CNKI (China National Knowledge Infrastructure), and CBM (Chinese biomedical Database) in order to seek RCTs related to LDCT or X-ray screening for lung cancer. The date of the last search was February 26, 2019. To obtain additional relevant studies, we also scanned conference proceedings and reference lists. The following search terms were used: "LDCT", "low dose helical CT", "low dose CT", "Lowdose spiral CT", "Low dose computed tomography", "lung neoplasm", "lung tumor", "lung carcinoma”, "lung cancer".

\section{Inclusion Criteria and Exclusion Criteria}

Each potentially eligible article was checked to see if they met all the following inclusion criteria: (1) the study design was a RCT (randomized controlled trial) comparing LDCT with x-ray or usual care; (2)participants were smokers who had been smoking $>15$ years or former smokers who stopped smoking 10 or 15 years ago; (3) participants were over 49 years old; (4) the data of all lung cancers, stage I lung cancers, lung cancer-specific mortality, all-cause mortality were reported in detail; (5) for duplicated publications on the same population, the most recent ones with the most complete data set were included. The exclusion criteria were as follows: (1) the screening only involved other risk factors, like asbestos; (2) the participants had a history of previous cancer with a clinically established diagnosis.

\section{Data extraction and quality assessment}

Two investigators independently extracted the following data for each eligible study: name of the study, first author, year of publication, sample size, trial randomization, age, sex, smoking history, screening in past years, screening times, screen interval, total follow-up time. If there was any dispute, it would be solved by a third independent reviewer. The NHS Critical Appraisal skills Programme (CASP) critical appraisal tool for RCTs was chosen for this meta-analysis as it covers sequence generation, allocation sequence concealment, blinding, incomplete outcome data, and selective outcome reporting ${ }^{7}$.

\section{Statistical Method}

The relative risk (RR), 95\% confidence interval (CI), and Forest Plot were produced using STATA14.0 to measure the effect of the low-dose CT screening on lung cancer. We calculated the Q-statistic $\left(\chi^{2}\right)$ and $I^{2}$ statistics to quantify the heterogeneity. Heterogeneity was classified as low, moderate, and high when the cut-off points of $I^{2}$ values reached $25 \%, 50 \%$, or $75 \%$ respectively ${ }^{8}$. If $I^{2}>50 \%$ ( $I^{2}$-statistic) or $P<0.1$ (Q-statistic), it indicated an obvious heterogeneity; then, the random-effect model (DerSimonian and Laid method $)^{9}$ would be used. Otherwise, the fixed-effects model (Mantel-Haenszel method) ${ }^{10}$ was used. Furthermore, subgroup analyses were conducted to explore the source of heterogeneity. The potential publication bias was assessed by using Begg's test ${ }^{11}$ and Egger's Test ${ }^{12}$, which might exist when $p<0.05$. Sensitivity analysis was used to search the extent to which inferences might depend on a particular study or group of studies. Differences were considered as statistically significant if two-sided $P$-values were less than 0.05.

\section{RESULTS}

\section{Characteristics of the eligible studies}

In order to identify all eligible studies, a comprehensive process was performed. A total of 1434 articles were collected and reviewed. After excluding duplicated papers, 1167 studies were left. Of these, 1107 were removed since they were found to be review studies or not on the topic after screening the title and/ or abstract. The remaining 60 full-text articles were assessed for eligibility. Eventually, 9 eligible articles were included in the final meta-analysis (Figure 1), and their details are presented in table $1^{3,13-20}$. Their quality ranged from moderate to high; most studies 
TABLE1. CHARACTERISTICS OF THE STUDIES INCLUDED IN THIS META-ANALYSIS.

\begin{tabular}{|c|c|c|c|c|c|c|c|c|c|}
\hline $\begin{array}{l}\text { Name } \\
\text { of the study }\end{array}$ & $\begin{array}{l}\text { Sample Size } \\
\text { (study: } \\
\text { control) }\end{array}$ & Control & Age & $\begin{array}{l}\text { Male } \\
(\%)\end{array}$ & $\begin{array}{l}\text { Smoking History } \\
\text { (py)/Former } \\
\text { Smokers (yr) }\end{array}$ & $\begin{array}{l}\text { Screening } \\
\text { interval } \\
\text { (year) }\end{array}$ & $\begin{array}{l}\text { Screen- } \\
\text { ing } \\
\text { times }\end{array}$ & $\begin{array}{l}\text { Median } \\
\text { screening } \\
\text { years }\end{array}$ & $\begin{array}{l}\text { Median } \\
\text { Follow-up } \\
\text { years }\end{array}$ \\
\hline NLST ${ }^{3,29} 2011$ & $53454(1: 1)$ & CXR & $55-74$ & 59.0 & $>30 /<15$ & 1 & 3 & 5 & 6.5 \\
\hline Danish $^{20} 2015$ & $4104(1: 1)$ & usual care & $50-70$ & 50.0 & $>20 /<10$ & 1 & 5 & 4.81 & $9.8^{*}$ \\
\hline Dante ${ }^{17} 2015$ & $2450(1: 1)$ & CXR & $60-74$ & 100.0 & $>20 /<10$ & 1 & 5 & 7 & 8.35 \\
\hline MILD'13 2012 & $4099(2: 2: 3)$ & usual care & $>65$ & 66.3 & $>20 /<10$ & $1 / 2$ & $5 / 3$ & 4.4 & 4.4 \\
\hline German'19 2015 & $4052(1: 1)$ & usual care & $50-69$ & 64.7 & $>15 /<10$ & 1 & 3 & 5 & 5 \\
\hline Depiscan ${ }^{\mathbf{1 4}} 2007$ & $765(1: 1)$ & CXR & $50-75$ & 70.7 & $>20 /<15$ & 1 & 1 & 2 & 2 \\
\hline LSS $^{16} 2004$ & $3318(1: 1)$ & CXR & $55-74$ & 59.0 & $>30 /<10$ & 1 & 2 & 2 & 2 \\
\hline ITALUNG ${ }^{18} 2017$ & $3206(1: 1)$ & usual care & $55-69$ & 65.2 & $>20 /<10$ & 1 & 4 & 9.3 & 9.3 \\
\hline China $^{15} 2018$ & $472(1: 1)$ & usual care & $55-74$ & - & $>30 /<15$ & 2 & 3 & 2 & 2 \\
\hline
\end{tabular}

py =pack-year *9.8person-y. The sex ratio in China was not displayed in the NLST criteria population concretely, but males were the majority.

\section{FIGURE 1.}
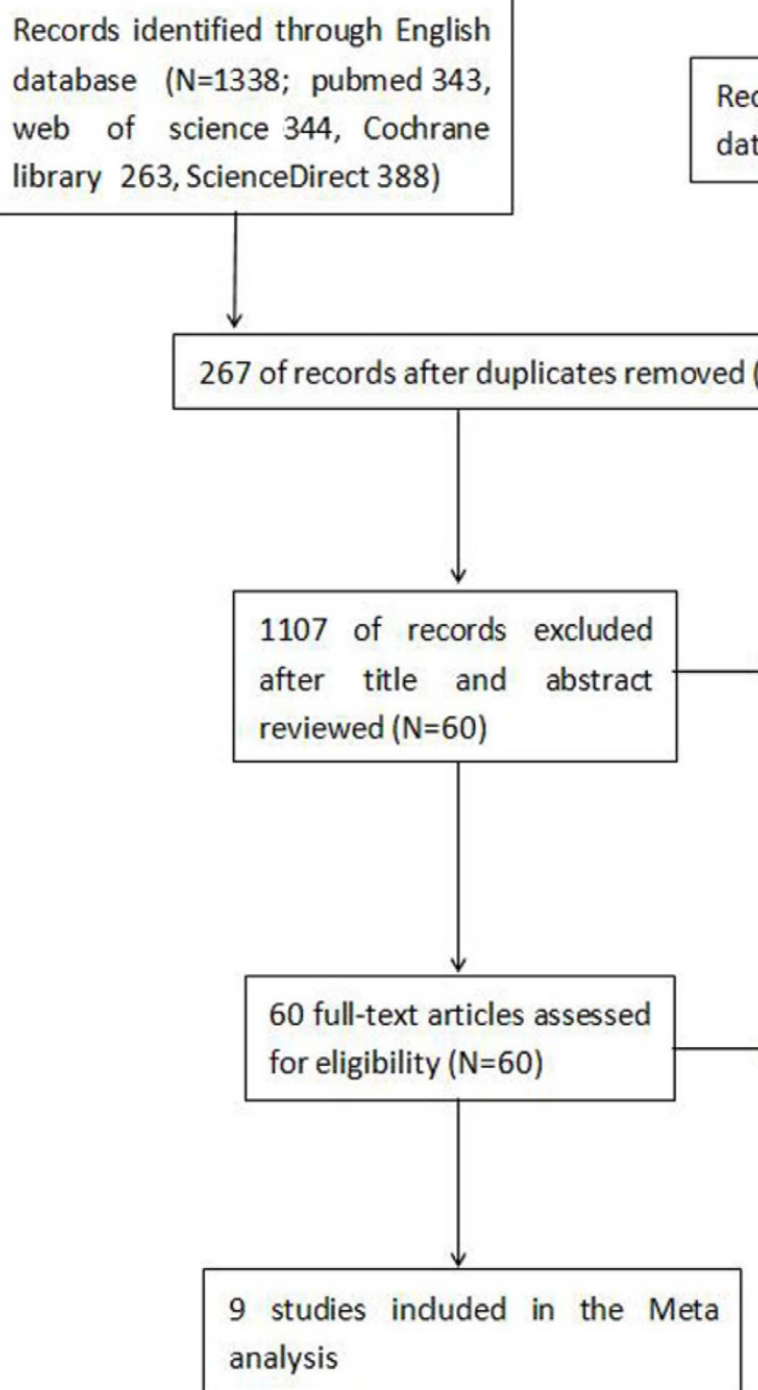

Records obtained from Chinese database ( $\mathrm{N}=96$; $\mathrm{CNKI73}, \mathrm{CBM} 23$ )
1107 of records excluded:

Review study ( $\mathrm{N}=115$ )

Not relevant studies ( $\mathrm{N}=992)$

51 of full-text articles exduded with reasons:

No eligible control or non-RCT $(\mathrm{N}=11)$

Duplicated data $(\mathrm{N}=36)$

Without complete follow-up $(\mathrm{N}=4)$ 


\section{FIGURE 2.}

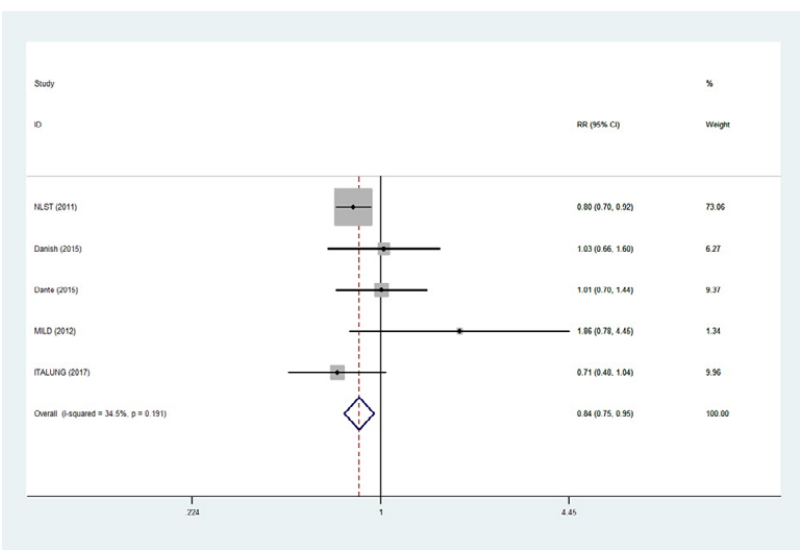

had explicit random assignment, concealed allocation, follow-up details, definite diagnosing criterion, and CT protocol. However, the double-blind could not be satisfied in the screening since the screening methods were evidently different between the treatment and control groups.

The nine studies included 38357 LDCT individuals and 37563 controls, both from high-risk lung cancer populations. The range of age was 50 to 70 years old; the average smoking history was 20 years, and the total screening years varied from 2 to 9.8 years. There were more males than females included in this analysis since most heavy smokers are male. The participants included in the meta-analysis were from Denmark, Italy, Germany, France, UK, China, and the United States.

\section{Detection rate of total lung cancers}

LDCT could find more lung cancers than the CXR or the no-screening group $(\mathrm{RR}=1.58,95 \% \mathrm{CI}=1.25-1.99$, $P<0.001)$, with high heterogeneity $\left(\chi^{2}=32.96, I^{2}=72.7 \%\right.$, $P<0.001)$. In the meta-analysis pooled result, we could find more lung cancers by screening no matter how long the total follow-up was, i.e., more than 5 years (RR=1.35, 95\% CI=1.06-1.72, $P=0.015)$ or less than 5 years $(\mathrm{RR}=2.16,95 \% \mathrm{CI}=1.59-2.95, P<0.001)$. The annual screening (RR=1.67, 95\%CI=1.25-2.24, $P<0.001)$ had a statistical significance in finding more lung cancers than biennial screening $(\mathrm{RR}=1.35,95 \% \mathrm{CI}=0.91-2.00$, $P=0.140$ ).

\section{Detection rate of stage I lung cancers}

The pooled data of stage I lung cancers indicated that more early-stage cancers can be found by LDCT screening ( $\mathrm{RR}=3.45,95 \% \mathrm{CI}=2.08-5.72, P<0.001$ ), with high Heterogeneity $\left(\chi^{2}=25.74, I^{2}=72.8 \%, P=0.001\right)$. The low dose CT, with absolute superiority, could find not only more lung cancers but also more stage I lung cancers.

After we proceeded to subgroup analyses regarding the detection rate of stage I lung cancers between the different types in the control group, we found there was no significant Heterogeneity in the CXR screening population $\left[I^{2}=0.0 \%, P=0.463\right]$.

\section{Lung Cancer-Specific Mortality and All-cause} mortality

Five studies reported Lung-Cancer-Specific Mortality. After merging, we found the protective effect in the LDCT group was statistically significant compared to the control group (RR=0.84, 95\%CI $=0.75-0.95$, $P=0.004)$, with moderate Heterogeneity $\left(\chi^{2}=6.11\right.$, $\left.I^{2}=34.5 \%, P=0.191\right)$. The merging result is presented in Fig 2. Six studies provided information on all-cause mortality. The results showed that there was no statistically significant difference between the two groups ( $\mathrm{RR}=1.26,95 \% \mathrm{CI}=0.89-1.78, P=0.193)$, with high Heterogeneity in the data $\left(\chi^{2}=99.08, I^{2}=95.0 \%, P<0.001\right)$.

Sensitivity Analysis and Publication bias evaluation

To assess the stability of the studies, we performed a sensitivity analysis using the leave-one-out method and reviewed the consistency of the results. We discarded each individual study to recalculate the Relative Risk. However, no single study influenced the pooled results significantly. Sensitivity analysis showed that the overall effect was evenly distributed in the trials included. The Begg's Test and Egger's Test were performed to evaluate publication bias of all the 9 studies. The results of Begg's Test (Begg's test: $\mathrm{P}=0.161$ ) showed that the potential publication bias had no obvious influence, but Egger's Test indicated publication bias (Eegg's test: $P<0.001$ ).

\section{DISCUSSION}

In this analysis, we calculated both the detection rate and mortality. The results demonstrated that the low-dose spiral CT had an absolute advantage compared to the CXR in lung cancer screening to find a higher proportion of lung cancers and stage-I cancers. Besides, it can provide a reduction of lung cancer-specific mortality in the low dose CT screening 
group. As to deaths due to all causes, it did not manifest a protective effect; this may be because smoking is a risk factor of many cardiovascular diseases, which were the cause of death for older smokers. Moreover, mortality for causes other than lung cancer revealed that screening has no effect in reducing these deaths. Our results are consistent with the meta-analysis by Cuiping FU et al. ${ }^{5}$ regarding reduced lung-cancer-specific mortality. Compared to the meta-analysis by Cuiping FU et al. who, after collecting information in 2013, published, in 2016, two RCT articles not included in this meta-analysis, the American feasibility study ${ }^{21}$ and the NELSON trial, ${ }^{22}$ since they did not have complete two-arm follow-up, nor did they report the results of the control group. The UK Lung Cancer Screenings in 2016 have not reported the results of the control group either ${ }^{23,24}$. To make the pooled results more reliable, the three RCT articles were not included in this analysis. Besides, the results did not vary greatly when adding the three studies in the meta-analysis. Furthermore, the lung cancer screening results of Danish, Dante, and Italung were updated in this analysis. Likewise, one 2015 study from German and one from China in 2018 were added in this analysis.

Then we considered the potential optimal interval of screening. The biennial screening has lower heterogeneity than the annual LDCT screening by subgroup analysis. Annual screening could find more lung cancers than chest-X rays or the no screening group, and the difference was statistically significant. However, the difference in lung cancer detection rate between the biennial screening and chest-X rays or the no screening group were not statistically significant. We also discussed the NELSON trial, in which the screening arm received LDCT screening at baseline, after 1,2 , and 2.5 years ${ }^{22}$. No significant differences were found in the detection rates between the 1-year and the 2-year interval screening, but stage distributions were different. Compared with 1-year interval screening, a lower proportion of stage I and a higher proportion of advanced (stage IIIb/IV) cancers were detected in the 2.5-year interval round; this difference was statistically significant. The 2.5 -year round showed no statistical significance in stage distributions compared with the 2-year round. This indicates that the 2.5 years interval is too long, which reduced the effect of the screening. However, in the MILD trial, there was no statistical difference in stage distribution or mortality between the annual and biennial CT screening ${ }^{13}$. Therefore, more qualified studies are needed to demonstrate the optimal interval of lung cancer screening.

Although lung cancer screening could detect more new lung cancers, its benefits and harms must be considered, such as the high rate of false positives and its cost-effectiveness, before widespread low-dose CT screening is implemented. In 2017, the European Union position statement declared that Lung cancer screening with low-dose CT could save lives, and it should start being implemented throughout Europe as soon as possible ${ }^{4}$.

Limitations of our study include the problem of the heterogeneity, which generally exists in many meta-analyses. What is more, a few articles did not have important data, which could not be obtained even after we wrote to the authors. Furthermore, the publication bias requires us to do more research with a higher-quality and larger sample. Furthermore, we only pooled the results of articles on smokers, but will other populations at risk of lung cancer benefit from CT screening? We could not draw a conclusion limited to finite studies. Some studies reported that screening might have an unintended health certificate effect in changing their lifestyle $\mathrm{e}^{25}$ and cause them to give up or reduce smoking habits ${ }^{26}$. This indicates that lung cancer screening should be accompanied by a smoking cessation intervention in widespread populations to reduce lung cancer mortality since smoking cessation is the best and the most cost-effective approach to reducing the risk of lung cancer ${ }^{27}$. Furthermore, the Dutch-Belgian Lung Cancer Screening trial (NEL$\mathrm{SON}$ ) is an ongoing randomized controlled trial that evaluates LDCT with a target of 10-year follow up ${ }^{22}$. NELSON will assess survival, quality of life, smoking cessation, and cost-effectiveness. We are waiting for the results.

\section{CONCLUSION}

In conclusion, LDCT screening for lung cancer has been demonstrated to reduce deaths from lung cancer in high-risk smokers. Given its high sensibility to find early-stage lung cancer, it is promising to identify and cure more lung cancers in the early stage. An annual LDCT screening is effective in finding more early-stage lung cancers. More studies on both the positive and negative aspects are required to enrich the conclusion and make further efforts to reduce morbidity and mortality from lung cancer. 


\section{Acknowledgments}

The authors thank colleagues in Anhui Medical University, BAO DONG for the help with methodology support, and YAN-JIE ZHANG for proofreading the article.

\section{Author's contributions}

Xue Tang and Wei Wu conceived the study. Xue
Tang, Lingling Wang, and Guangbo Qu oversaw data collection. Xue Tang conducted the analysis. Xue Tang drafted the manuscript, and all authors contributed to its critical review. Xue Tang assumes overall responsibility for the paper. The authors thank colleagues at the Anhui Medical University, BAO DONG for the help with methodology support, and YAN-JIE ZHANG for support in the literature search.

\section{RESUMO}

OBJETIVO: O câncer de pulmão é a principal causa de mortes relacionadas ao câncer. Para reduzir a mortalidade por câncer de pulmão e encontrar câncer de pulmão em um estágio inicial, é necessária uma triagem por tomografia de baixa dose. Uma meta-análise foi emitida para testemunhar se a triagem poderia reduzir a mortalidade por câncer de pulmão e investigar o melhor programa de triagem.

MÉTOdos: Pesquisamos PubMed, Web of Science, biblioteca Cochrane, ScienceDirect e relevante banco de dados chinês. Ensaios clínicos controlados aleatórios, em que os participantes eram fumantes com mais de 49 anos (tabagismo >15 anos ou parar de fumar 10 ou 15 anos atrás) foram incluídos.

RESULTADOS: Nove estudos RCT preencheram os critérios. O rastreamento de LDCT pôde encontrar mais cânceres de pulmão (RR=1,58, IC 95\%=1,25-1,99, $P<0,001)$ e mais cânceres de estágio I do pulmão ( $R R=3,45$, IC 95\%=2,08-5,72, $P<0,001)$ em comparação com raio $X$ do tórax ou nenhum grupo de triagem. Ele indicou uma redução estatisticamente significativa na mortalidade específica do câncer de pulmão ( $R R=0,84$, IC 95\%=0,75-0,95, $P=0,004)$, mas sem uma redução estatisticamente significativa na mortalidade por todas as causas ( $R R=1,26$, IC 95\%=0,89-1,78, $P=0,193)$. Anualmente, o rastreamento de LDCT foi sensível em encontrar mais cânceres de pulmão.

CONCLUSÕES: A triagem de TC de baixa dose é eficaz para encontrar mais cânceres de pulmão e diminuir as mortes por câncer de pulmão. Para encontrar mais cânceres de pulmão em estágio inicial, a triagem anual de tomografia de baixa dose pode ser melhor do que a triagem bianual.

PALAVRAS-CHAVE: Ensaio clínico controlado aleatório. Meta-análise. Triagem. Detecção precoce de câncer. Tomografia computadorizada por raios $X$

\section{REFERENCES}

1. Didkowska J, Wojciechowska U, Mańczuk M, Lobaszewski J. Lung cance epidemiology: contemporary and future challenges worldwide. Ann Transl Med. 2016;4(8):150.

2. Ferlay |, Soerjomataram I, Dikshit R, Eser S, Mathers C, Rebelo M, et al. Cancer incidence and mortality worldwide: sources, methods and major patterns in GLOBOCAN 2012. Int | Cancer. 2015;136(5):E359-86.

3. National Lung Screening Trial Research Team, Aberle DR, Adams AM, Berg CD, Black WC, Clapp JD, Fagerstrom RM, et al. Reduced lung-cancer mortality with low-dose computed tomographic screening. N Engl | Med. 2011;365(5):395-409

4. Oudkerk M, Devaraj A, Vliegenthart R, Henzler T, Prosch H, Heussel CP, et al. European position statement on lung cancer screening. Lancet Oncol. 2017;18(12):e754-66

5. Fu C, Liu Z, Zhu F, Li S, Jiang L. A meta-analysis: is low-dose computed tomography a superior method for risky lung cancers screening population? Clin Respir J. 2016;10(3):333-41.

6. Field JK, Baldwin DR, Devaraj A, Oudkerk M. EUPS-argues that lung cancer screening should be implemented in 18 months. Br J Radiol. 2018;91(1090):20180243.

7. Critical Appraisal Skills Programme. 11 questions to help you make sense of a trial, 2013. [cited 2019 Feb 5]. Available from: http://www.casp-uk.net/ casp-tools-checklists

8. Higgins JP, Thompson SG, Deeks |J, Altman DG. Measuring inconsistency in meta-analyses. BMJ. 2003;327(7414):557-60.

9. DerSimonian R, Laird N. Meta-analysis in clinical trials. Control Clin Trials. 1986:7(3):177-88
10. Mantel N, Haenszel W. Statistical aspects of the analysis of data from retrospective studies of disease. J Natl Cancer Inst. 1959;22(4):719-48.

11. Begg CB, Mazumdar M. Operating characteristics of a rank correlation test for publication bias. Biometrics. 1994;50(4):1088-101.

12. Egger M, Davey SG, Schneider M, Minder C. Bias in meta-analysis detected by a simple, graphical test. BMJ. 1997;315(7109):629-34.

13. Pastorino U, Rossi M, Rosato $V$, Marchiano A, Sverzellati N, Morosi $C$, et al. Annual or biennial CT screening versus observation in heavy smokers: 5 -year results of the MILD trial. Eur I Cancer Prev. 2012;21(3):308-15.

14. Blanchon T, Bréchot IM, Grenier PA, Ferretti GR, Lemarié E, Milleron $B$, et al; Dépiscan Group. Baseline results of the Depiscan study: a French randomized pilot trial of lung cancer screening comparing low dose CT scan (LDCT) and chest X-ray (CXR). Lung Cancer. 2007;58(1):50-8.

15. Yang W, Qian F, Teng J, Wang H, Manegold C, Pilz LR, et al. Community-based lung cancer screening with low-dose CT in China: results of the baseline screening. Lung Cancer. 2018;117:20-6.

16. Gohagan JK, Marcus PM, Fagerstrom RM, Pinsky PF, Kramer BS, Prorok $P C$, et al. Final results of the Lung Screening Study, a randomized feasibility study of spiral CT versus chest $X$-ray screening for lung cancer. Lung Cancer. 2005;47(1):9-15.

17. Infante M, Cavuto S, Lutman FR, Passera E, Chiarenza M, Chiesa G, et al; DANTE Study Group. Long-term follow-up results of the DANTE trial, a randomized study of lung cancer screening with spiral computed tomography. Am J Respir Crit Care Med. 2015;191(10):1166-75. 
18. Paci E, Puliti D, Lopes Pegna A, Carrozzi L, Picozzi G, Falaschi F, et al. Mortality, survival and incidence rates in the ITALUNG randomised lung cancer screening trial. Thorax. 2017;72(9):825-31.

19. Becker N, Motsch E, Gross ML, Eigentopf A, Heussel CP, Dienemann H, et al. Randomized study on early detection of lung cancer with MSCT in Germany: results of the first 3 years of follow-up after randomization. Thorac Oncol. 2015;10(6):890-6.

20. Wille M, Dirksen A, Ashraf H, Saghir Z, Bach KS, Brodersen J, et al. Results of the randomized Danish lung cancer screening trial with focus on high-risk profiling. Am J Respir Crit Care Med. 2016;193(5):542-51.

21. Garg K, Keith RL, Byers T, Kelly K, Kerzner AL, Lynch DA, et al. Randomized controlled trial with low-dose spiral CT for lung cancer screening: feasibility study and preliminary results. Radiology. 2002;225(2):506-10.

22. Yousaf-Khan $U$, van der Aalst $C$, Jong PA, Heuvelmans M, Scholten E, Lammers JW, et al. Final screening round of the NELSON lung cancer screening trial: the effect of a 2.5-year screening interval. Thorax. 2017;72(1):48-56
23. Field IK, Duffy SW, Baldwin DR, Brain KE, Devaraj A, Eisen T, et al. The UK Lung Cancer Screening Trial: a pilot randomised controlled trial of low-dose computed tomography screening for the early detection of lung cancer. Health Technol Assess. 2016;20(40):1-146.

24. Baldwin DR, Duffy SW, Wald NJ, Page R, Hansell DM, Field JK. UK Lung Screen (UKLS) nodule management protocol: modelling of a single screen randomised controlled trial of low-dose CT screening for lung cancer. Thorax. 2011;66(4):308-13.

25. van der Aalst $\mathrm{CM}$, van Klaveren $\mathrm{R}$, Koning H]. Does participation to screening unintentionally influence lifestyle behaviour and thus lifestyle-related morbidity? Best Pract Res Clin Gastroenterol. 2010;24(4):465-78.

26. Filippo L, Principe R, Cesario A, Apolone G, Carleo F, lalongo P, et al. Smoking cessation intervention within the framework of a lung cancer screening program: preliminary results and clinical perspectives from the "Cosmos-II" Trial. Lung. 2015;193(1):147-9.

27. Tota JE, Ramanakumar AV, Franco EL. Lung cancer screening: review and performance comparison under different risk scenarios. Lung. 2014;192(1):55-63. 